Mosul Journal of Nursing

www.mjn.mosuljournals.com

\title{
Assessment of internal fixation outcomes among fractured patient in Mosul City
}

Article information

Article history:

Received January 14, 2018

Accepted February 1, 2018

Available online April 15, 2018

\section{DOI: 10.33899/min.2018.160077 @2020, College of Nursing, University of Mosul. Creative Commons Attribution 4.0 International License \\ https://mjn.mosuljournals.com/article 160077.html}

Mohammed Tariq Ali ${ }^{1}$

\begin{abstract}
Background and Aim: Internal fixation is a surgical intervention in orthopedics that involves the surgical implementation of doing a manegments and repairing for bone, this concept starting in the mid of 19th century and was made a doable as routine surgical treatment in the mid of 20th century, that operation may be made by special equpment like stainless steel or titanium, the study assessed outcome of internal fixation.

Material and method: cross-sectional (descriptive) design, 110 patients were participate in this study which conducted at $\mathrm{Al}$ - Salam Hospital Teaching and AlJumhory Teaching Hospital from $10^{\text {th }}$ December 2013 to $7^{\text {th }}$ April 2014, The study tool composed of three parts; part one demographic characteristics of the patients including age, gender, residence, past history (family history, medical history) and economic status, Part Two; Fractures classification consist of five items; types of fractures location of fracture mechanism of trauma, duration of internal fixation and Part Three(Internal fixation outcome)consist of three items (complete healing without complication, failure of internal fixation, delayed definitive fixation).

Results:80.9 of patients was suffering from complete fracture, Femur was the most commonly location of fracture which constitute $56.3 \%$ of patients, the majority of fractures were caused by blunt and motor vehicle collisions constitute $40.9 \%$ and $31.8 \%$ respectively. More than half of the patients were achieved internal fixation without complications while $43.8 \%$ of patients were suffered from joint stiffness more than one month post-operatively.

Conclusion: rigged internal fixation lead to good healing therefore more than half of patients was completely healing with variation in time, while failure of internal fixation was about quarter of study sample caused by complication.
\end{abstract}

\footnotetext{
${ }^{1}$ Assist. Lecturer / College of Nursing / University of Mosul / albark66@ yahoo.com
} 
Recommendation: Encourage to use internal fixation procedure less than 30 days after fractures and applying internal fixation for more than one year to avoid nonunion complication.

Keyword : Internal fixation, Outcome, Assessment, Fracture .

\section{INTRODUCTION}

Background: is a break in the continuity of the bone. A bone fracture can be the result of high force impact or stress, or trivial injury as a result of certain disease conditions which are led to weaken the bones, such as osteoporosis and bone cancer, or osteogenesis imperfecta, where the fracture is then properly termed a pathologic (Marshall and Browner, 2012).

There are many types of fractures, but the main categories are displaced, nondisplaced, open, and closed. Displaced and non-displaced fractures refer to the way the bone breaks.

Operative treatment of the fracture is challenging due to both the complex shape of the bone and the limited soft tissue available, there is evidence that surgically treated patients heel faster and return more quality to their previous activities than those with a conservatively treated fracture (Sterens, et al 2001).

Internal fixation is an operation in orthopedics that involves the surgical intervention of implants for repairing a bone,

this concept starting in the mid of 19th century and was made a doable as routine surgical treatment in the mid of 20 th century, internal fixator may be made of stainless steel or titanium (Schlich, 2002).

Types of internal fixators include bone screws and metal plates, pins, rods, Kirschner wires and intramedullary devices for example the Kuntscher nails and inter locking nail (Medicine Net, 2010).

Risk of fracture depends, in part, on your age. Broken bones are very common in childhood, though children's fractures are generally less complicated than fractures in adults. As you age, your bones become more brittle and you are more likely to suffer fractures from falls that would not occur when you were young (Whittle, 2008).

The goal of treatment in open fractures is to prevent infection, promote fracture healing and restore normal limb alignment and function. Complications are rare, but no procedure is

completely free of risk. If you are planning to have this procedure, your doctor will review a list of possible complications, which may include Infection, Bleeding, Reaction to anesthesia and Blood clots (Song, et al 2008).

Complications of internal fixation include pin tract infection, pin loosening or breakage, interference with joint motion, neurovascular damage when pins are placed, malalignment caused by poor placement of the fixator, delayed union, and malunion (Dorothy and Liddel, 2010).

\section{Rationale of the study:}

1. There were $(10 \%)$ of patient with major complications and (18\%) of patients with minor complications, There were $(6.7 \%)$ with both major and minor complications (Widjaja, et al 2007).

2. Negative outcomes in many patients lead to internal fixation failure, about (25\%) of patients after internal fixation sustained a failure of fixation (Mendelsohn, et al 2013).

3. Relating to bad security situation and low safety level in our country the accidents has significantly increased so there is need to study about this. 


\section{Mosul Journal of Nursing, Vol. 8, No. 2, 2020 ( 9-16 )}

Aim: to assess outcome of internal fixation.

Objective of the study:

1. To assess socio demographic data of the study stander

2. To identify causes and associated sign of fracture among study simple.

3. To classify the outcome of internal fixation among fracture patient.

Term definitions:

Assessment: Is a gathering and analyzing information that will affect the health of the people to be served (Judith and Babara, 2005).

Internal fixation: surgical itervention is doing to repairing bone, an internal fixator may be made of stainless steel or titanium (Sterens, et al 2001).

Outcomes: study of the results of health services experiences, the result of an experiment in probability theory. http://en.wikipedia. org/wiki/Outcomes.

\section{MATERIALS AND METHOD}

\section{Ethical considerations}

\section{Administrative arrangement}

Prior to collection of data, official permission was obtain from the University of Mosul/ Nursing College/ Research committee. (Appendix A)

\section{Consent form to the sample}

Ethical issue was obtain from all patients and only who are agree to participate in the study were chosen. (Appendix B)

\section{Design of the study}

To achieve study aim (objectives) nonexperimental (cross-sectional) descriptive design was applied.

Period of the study and data collection

The study was conducted from $10^{\text {th }}$ December 2013 to $7^{\text {th }}$ April 2014.

Working plan has been setup in order to execute the research work. The progress steps explaining in the details of this work include the following steps:

a- The submission of the questioner to include patient and interviews with these patients has been executed and then the collected questioners and then analyzed and transmitted in to a computer data program prepared for this mission (one month).

b- The collected data after analyzing is fed in an excel special computer processing data analyzer and the results were drawn and a required table as well ( one month)

\section{Study Setting}

This study was conducted at Al - Salam Hospital Teaching and Al- Jumhory Teaching Hospital in Mosul city.

Sample and sampling of the study

Non-probability simple random (Convenience) sampling technique was used in this study; (110) patients was selected from fracture department and emergency department in mentioned hospitals, Sample size calculation was done through power analysis.

\section{The study tool}

Researchers and supervisor built the study tool, expert was asked for their opinions, all modification by expert was done. The study tool composed of three parts:

Part One: cover demographic characteristics of the patients including age, gender, residence, past history (family history, medical history) and economic status.

Part Two: Fractures classification; include five items( types of fractures include: complete, incomplete, simple, comminuted),location of fracture include ( redus , ankle, clavicle ,femur , humerus, patella , spine ,tibia, ulna ), mechanism of trauma include ( penetrating , blunt ,motor vehicle collisions, sporting activities and other mechanism) and duration of internal fixation ranging from less than 6 months to one year.

Part Three: Internal fixation outcome; include three items (complete healing without complication, failure of internal fixation, delayed definitive fixation), complications include 9 items (Nonunion, DVT, joint stiffness, limping, bed ulcer, osteoporosis, keloid 
scar, muscle wasting and infection). (Appendix C).

\section{Validity}

To ensure the validity of the tool, (10) experts was chosen to evaluate the proposed plan of the study tool, their opinions, suggestions and recommendations were depended to adapt and direct the study plan. (Appendix D).

\section{Reliability}

Cronbach's alpha coefficient was used to test the reliability of the questionnaire dimensions. Reliability of the study tools was determined by split half $=0.76$.

\section{Data analysis :}

Data are prepared and entered into a computer files; Statistical Program for the Social Science (SPSS, version 21) was used to analysis of data results. Data are analyzed through the application of descriptive data analysis approach (Frequencies and Percentages).

Barriers of the study:

Difficulty in collecting ethical consent from health office.

1. Difficulty in collecting information from patients because they are tired.

2. Unavailability of national previous studies similar to this study.

\section{RESULTS}

Table (1) Demographical elements of the Study participants.

\begin{tabular}{|c|c|c|c|}
\hline \multicolumn{2}{|c|}{ Variables } & No. & $\%$ \\
\hline \multirow{5}{*}{ Age } & Less than 15 years & 13 & 11.8 \\
\hline & 15-29 Years & 41 & 37.3 \\
\hline & 30-44 Years & 26 & 23.6 \\
\hline & 45-59 Years & 17 & 15.5 \\
\hline & More than 60 Years & 13 & 11.8 \\
\hline \multicolumn{2}{|l|}{ Total } & 110 & 100 \\
\hline \multirow{2}{*}{ Gender } & Male & 67 & 60.9 \\
\hline & Female & 43 & 39.1 \\
\hline \multicolumn{2}{|l|}{ Total } & 110 & 100 \\
\hline \multirow{2}{*}{ residence } & Rural & 56 & 50.9 \\
\hline & Urban & 54 & 49.1 \\
\hline \multirow[t]{2}{*}{ Total } & & 110 & 100 \\
\hline & No Past History & 96 & 87.3 \\
\hline \multirow[t]{2}{*}{ Past History } & Medical History & 3 & 2.7 \\
\hline & Surgical History & 11 & 10 \\
\hline Total & & 110 & 100 \\
\hline \multirow{4}{*}{$\begin{array}{c}\text { Economic } \\
\text { Status }\end{array}$} & Good & 3 & 2.7 \\
\hline & Moderate & 57 & 51.8 \\
\hline & Poor & 50 & 45.5 \\
\hline & & 110 & 100 \\
\hline
\end{tabular}

Table (2) Distribution of the fractures classification.

\begin{tabular}{ll|cc}
\hline \multicolumn{2}{c|}{ Items } & No. & \% \\
\hline \multirow{3}{*}{ Type of the Fracture } & Complete & 89 & 80.9 \\
& Incomplete & 4 & 3.6 \\
Total & Simple & 2 & 1.8 \\
& Comminuted & 15 & 13.7 \\
& & 110 & 100
\end{tabular}


Mosul Journal of Nursing, Vol. 8, No. 2, 2020 ( 9-16 )

\begin{tabular}{cl|cc} 
& Radial & 13 & 11.8 \\
& Ankle & 7 & 6.4 \\
& Clavicle & 1 & 0.9 \\
Location of Fracture & Femur & 62 & 56.3 \\
& Hummers & 17 & 15.5 \\
& Patella & 4 & 3.6 \\
& Tibia & 2 & 1.8 \\
& Ulnar & 4 & 3.6 \\
& Total & 110 & 100 \\
& Penetrating & 12 & 10.9 \\
& Blunt & 45 & 40.9 \\
Causes of Fracture & motor vehicle & 35 & 31.8 \\
& collisions & 7.3 \\
Total & sporting activities & 9 & 8.2 \\
& other mechanisms & 110 & 100 \\
Duration of Fracture & & 34 & 30.9 \\
& Less than 10 days & 26 & 23.6 \\
Total & 10-19 days & 8 & 7.2 \\
& 20-29 days & 42 & 38.3 \\
Duration of internal fixation & More than 30 days & 110 & 100 \\
& & 57 & 51.9 \\
Total & Less than 6 months & 32 & 29.1 \\
& 12- less than 12 months & 13 & 11.8 \\
& 18-24 months & 8 & 7.2 \\
& & 110 & 100
\end{tabular}

Table (3) Distribution of outcomes and complications of the fractures.

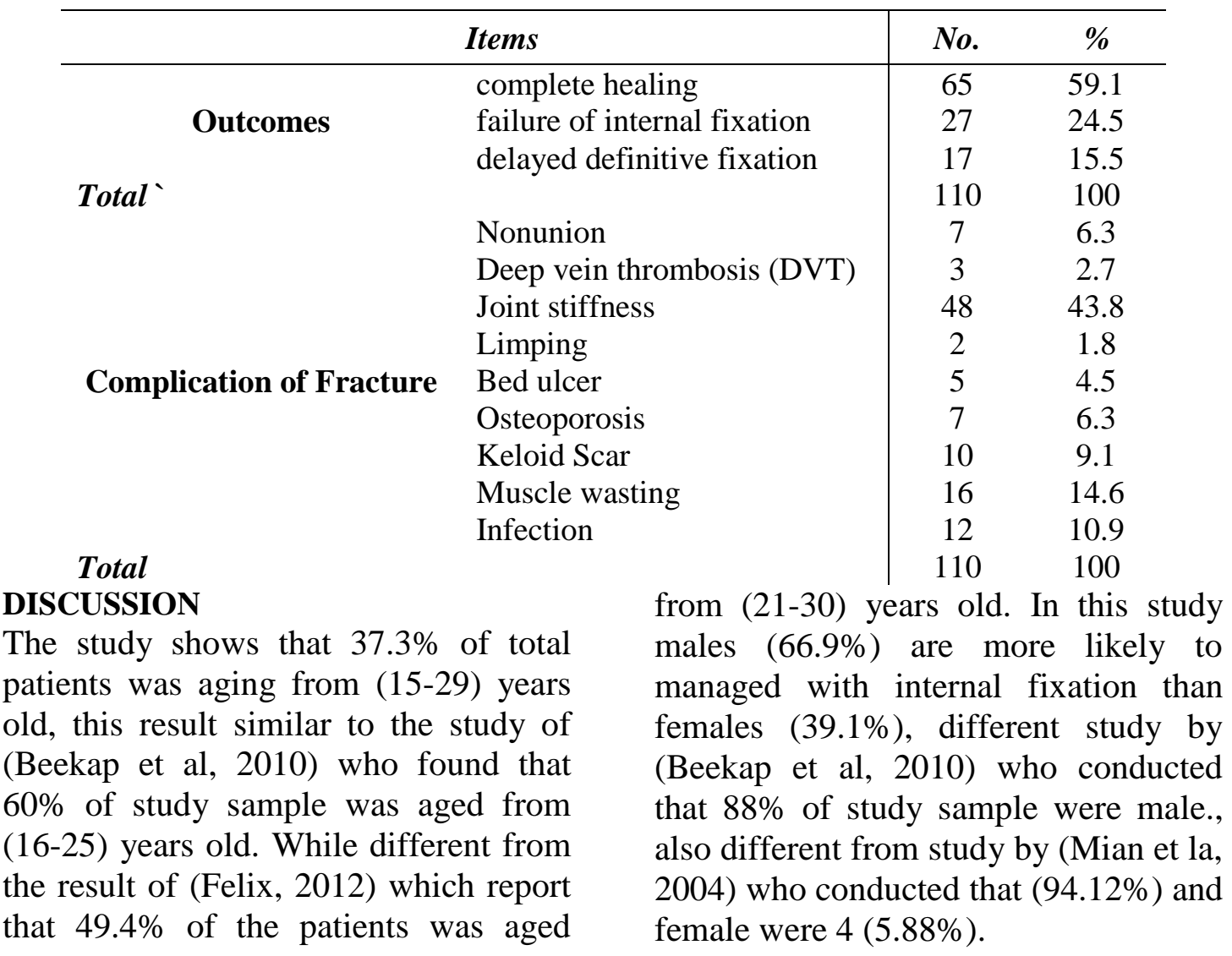




\section{Mosul Journal of Nursing, Vol. 8, No. 2, 2020 ( 9-16 )}

Concerning to type of fractures; the majority of the sample has complete fracture constituting $80.9 \%$ followed by $13.7 \%$ comminuted fracture, similar study by (Felix, 2012) who present that the classification of fractures was incomplete, complete and comminuted type were encountered in $27.5 \%, 38.5 \%$ and $15.4 \%$ respectively, also similar to study by (Beekap et al, 2010) who found that the majority of patients $40 \%$ was suffer from comminuted fracture. In the study femur fracture was the highest location for fractures which constituted $56.3 \%$ followed by hummers $15.5 \%$ and $11.8 \%$ radial while $1.8 \%$ for tibia and $3.6 \%$ for ulna and patella, this study supported by (Beekap et al, 2010) who found that $3.3 \%$ of fractures was patella and $6.6 \%$ for both tibia and fibula fractures. Relating to security situation in Iraq (accidents of explosions and gunfire) the most causes for fractures in this study were blunt injuries $(40.9 \%)$ followed by motor vehicle collisions $(31.9 \%)$ this result similar to study by (Mian et la, 2004) who revealed that fracture has high velocity from gunshot injury. Also similar to study by (Daniel, et al 2008) that revealed that the majority of injuries mechanisms was blunt which constituted $68 \%$ of study sample. The result conducted that the duration of fractures was $38.3 \%$ more than 30 days while $30.9 \%$ for less than 10 days, this result not supported by (Beekap et al, 2010) who present $70 \%$ of study fractures was duration form 10-20 days and $13.3 \%$ of fractures' duration were more than 30 days.

The study shows that $43.8 \%$ of fractures' complications was joint stiffness, $\quad 6.3 \%$ nonunion, $10.9 \%$ infection and $1.8 \%$ limping, this result similar to the study by (Mian et la, 2004) who found that complication of interlocking was $10.3 \%$ for infection, $2.9 \%$ for limb shortening, $5.8 \%$ for nonunion and $7.3 \%$ for knee stiffness.
While different from study by (Beekap et al, 2010) who found that the postoperatively complication followed interlocking nailing was $16.6 \%$ for superficial infection, $33.3 \%$ for restriction of knee flexion and $6.6 \%$ for delayed union with no evidence of nonunion and mal-union.

Of all patients $59.1 \%$ they were completely healing while $15.5 \%$ has delayed healing and $24.5 \%$ failed in healing, this result not supported by (Mian et la, 2004) who found $4.4 \%$ failure of interlocking were recorded.

\section{CONCLUSION}

The majority of patients was suffering from complete fractures; femoral bone was the most comment of internal fixation followed by hummers.

Blunt injuries and motor vehicle accidents was the most common causes for fractures among study sample, rigged internal fixation lead to good healing therefore more than half of patients was completely healing with variation in time, while failure of internal fixation was about quarter of study sample caused by complication.

A half of sample after internal fixation was complicated as Joint stiffness, while the less complication was the limping.

\section{RECOMMENDATIONS}

1. Encourage to use internal fixation procedure less than 30 days after fractures and applying internal fixation for more than one year to avoid nonunion complication.

2. Advice patients about the benefit of exercises (flexion and extension) that can decrease the joint stuffiness.

3. Observation of ready back drainage and change of dressing to decrease infection, elevate lower extremity to avoid edema and thrombosis after fixation.

\section{REFERENCES}

B. Widjaja MB BS; K. Eng MB BS; J.

Griffiths MB BS, FRACS. (2007) 
complications of internal fixation in paediatric fractures. ANZ Journal of Surgery, 10(77), P. 873-876.

Daniel, J., Stinner, M.D., James A., Keeney, M.D., Joseph R. (2008). Outcomes of Internal Fixation in a Combat Environment. Southern Orthopaedic Association, 19(1), P. 5052.

Deepak. M. K., Karun J., Kumardev A., Rajamanya, Pratik R., Gandhi, C. S., Rupakumar. R., Ravishankar. (2010). Functional outcome of diaphyseal fractures of femur managed by closed intramedullary interlocking nailing in adults, Annals of African Medicine, (11), P.54-56.

Dorothy B. Liddel, 2010. Medical surgical nursing, Musculoskeletal disorders. (11th ed), P. 1943- 1955.

Felix Senzighe Mrita.(2012). ShortTerm Outcome of Patients With Closed Comminuted Femoral Shaft Fracture Treated With Locking Intramedullary Sign Nail At Muhimbili Orthopaedic Institute (MOI), Master of Medicine in Orthopaedics, P. 23-29. http://en.wikipedia.org/wiki/Outcomes. Judith A and Babara W. (2005). Community health nursing. Definition of terms. $\left(6^{\text {th }}\right.$ ed). Lippincott Williams \& Wilkins; 157.

Marshall. S.T. and Browner B.D. (2012). Emergency care of musculoskeletal injuries. In Courtney M. Townsend Jr. Sabiston textbook of surgery: the biological basis of modern surgical practice. Elsevier, pp. 480520.

MedicineNet.com URL: http:// www.medterms.com/script/main/art.asp ? Article key=13714 Accessed 9 January 2010.

Mendelsohn, E.S Hoshino, C.M., Harris, T.G., Zinar, D.M. (2012). The effect of obesity on early failure after operative syndesmosis injuries, 27(4):201-6.

Mian, A., Syed, A. H., Muhammad, S. K., (2008). Evaluation of Results of Interlocking Nails in Femur Fractures due to High Velocity Gunshot Injuries. J Ayub Med Coll Abbottabad, 20(1); P.16-19.

Schlich. T. (2002) Surgery, Science and Industry. A Revolution in Fracture Care, 1950s-1990s (Houndsmills, Basingstoke: Palgrave).

Song, K. S., Kang, C. H., Min, B. W., Bae, K. C., Cho, C. H., Lee, J. H. (2008). "Closed Reduction and Internal Fixation of Displaced Unstable Lateral Condylar Fractures of the Humerus in Children". The Journal of Bone and Joint Surgery 90 (12), 2673-2681. doi:10.2106/JBJS.G.01227. PMID 19047713 .

Sterens D.G., Behary .R., Mckee M.D., et al. (2001). The long-terms functional outcome of operativerly treated tibial plateau fractures. J Orthop Trauma, 15. P. 312-320.

Whittle A.P. (2008). Fracture of the lower extremity In: Canale ST, Beaty JH, editors. Campbell's operative 
Mosul Journal of Nursing, Vol. 8, No. 2, 2020 ( 9-16 )

orthopaedics. (11th ed). Philadelphia: Mosby publishers, p. 3190-2 